\title{
Alginic acid sodium hydrogel co-transplantation with Schwann cells for rat spinal cord repair
}

Haibao Wang ${ }^{1}$, Chibo Liu², Xueqiang Ma ${ }^{1}$

1Department of Surgery, Taizhou Municipal Hospital, China

2Department of Clinical Laboratory, Taizhou Municipal Hospital, China

Submitted: 27 October 2011

Accepted: 11 January 2012

Arch Med Sci 2012; 8, 3: 563-568

DOI: 10.5114/aoms.2012.29412

Copyright (c) 2012 Termedia \& Banach

\author{
Corresponding author: \\ Xueqiang Ma MD, PhD \\ Department of Surgery \\ Taizhou Municipal Hospital \\ Taizhou \\ Zhejiang 318000 China \\ E-mail: \\ xueqiang_ma@yahoo.cn
}

\begin{abstract}
Introduction: The aim of the study was investigating the influence of Schwann cellsalginic acid sodium hydrogel co-transplantation on a rat model of spinal cord injury. Material and methods: Sprague-Dawley (SD) rats were randomly assigned to 4 groups: control, injury, injury with Schwann cell transplantation, and injury with Schwann cells-alginic acid sodium hydrogel co-transplantation. Gelatin sponge blocks containing a Schwann cell suspension were transplanted into the injury site in the Schwann cell group; Schwann cells seeded in alginic acid sodium hydrogel were transplanted into the injury site in the Schwann cells-alginic acid sodium hydrogel group. At $12 \mathrm{~h}, 1,3,7$, and 21 days after surgery, animals were assessed on the Basso, Beattie and Bresnahan (BBB) locomotor rating scale and then were sacrificed.

Results: In the injury group, Bcl-2 immunoreactive cells peaked at 3 days after surgery, and the expression level returned to normal level at 14 days. In the co-transplantation group, $\mathrm{Bcl}-2$ immunoreactive cells in the spinal cord-transected segments were significantly increased until 7 days $(p<0.05)$ and remained at this level for more than 14 days. In the injury group, the number of apoptotic cells was the highest, as compared with the other 3 groups, and peaked at 1 and 7 days following spinal cord injury, and they were mostly distributed in the white matter. The BBB scores were significantly higher in the Schwann cells-alginic acid sodium hydrogel transplantation group than in the simple injury and Schwann cell groups $(p<0.05)$.

Conclusions: Schwann cells-alginic acid sodium hydrogel co-transplantation could inhibit cellular apoptosis and enhance Bcl-2 expression in the spinal cord-transected segments, and thereby promote the recovery of locomotor function after spinal cord injury, although it did not reach full rehabilitation.
\end{abstract}

Key words: Schwann cell, spinal cord injury, co-transplantation, BBB score, Bcl-2, apoptosis, alginic acid sodium hydrogel.

\section{Introduction}

Schwann cell transplantation has been shown to promote the recovery of locomotor function after spinal cord injury [1, 2]. Selection of proper vectors for Schwann cell co-transplantation has been shown to be more propitious to exert the function of Schwann cells [3, 4]. Many types of gels seeded with Schwann cells have been investigated, showing improved survival of Schwann cells. However, alginic acid sodium hydrogel has not been studied for its potential application in Schwann cell co-transplantation for spinal cord injury repair.

In the present study, Schwann cells and alginic acid sodium hydrogel were co-transplanted into spinal cord-transected segments to observe cel- 
lular apoptosis and Bcl-2 expression and to investigate the recovery of lower limb locomotor function in a rat model of spinal cord injury.

\section{Material and methods}

\section{Design}

A randomized controlled animal experiment.

\section{Time and setting}

This study was performed at the Laboratory of Nerve Injury and Regeneration, Medical College, Nanchang University between June 2006 and June 2007. The study was approved by the local animal experiment committee.

\section{Materials}

A total of 120 adult Sprague-Dawley (SD) rats of either gender, weighing 220-250 g, as well as 10 additional neonatal SD rats, were provided by the Laboratory Animal Center, Medical College, Nanchang University and were included in this study. The experimental protocol was in accordance with the Guidance Suggestions for the Care and Use of Laboratory Animals formulated by the Ministry of Science and Technology of China. Alginic acid sodium was purchased from Sigma, USA.

\section{Methods}

Isolation, culture, and purification of Schwann cells Schwann cells were isolated, cultured, and purified according to previously published methods $[5,6]$. Briefly, the bilateral sciatic nerves of neonatal SD rat pups at day 2 were dissected and washed with PBS. Then the epineurium of each nerve was stripped under the stereo-microscope. The nerves were cut into small pieces $(<1 \mathrm{~mm})$ and dissociated using $2 \mathrm{U} / \mathrm{ml}$ type I collagenase (Sigma, Shanghai) for $30 \mathrm{~min}$ followed with $0.25 \%$ trypsin (Sigma, Shanghai) at $37^{\circ} \mathrm{C}$ for $10 \mathrm{~min}$. Then the suspension was centrifuged at $1000 \mathrm{r} / \mathrm{min}$ for $8 \mathrm{~min}$ to isolate the cells. Then the cells were placed into $25 \mathrm{~mm}^{2}$ culture flasks (Shenggong, Shanghai) and incubated with Dulbecco's Modified Eagle's Medium (DMEM, Gibco, Shanghai) with $10 \%$ fetal bovine serum (FBS, Gibco, Shanghai) and antibiotics (penicillin, Shenggong, Shanghai). Antimitotic agent was used for 2-3 days to remove fibroblasts. Finally the identity of Schwann cells was confirmed with S-100 protein immunostaining. The purity of cultured Schwann cells was more than $96 \%$.

\section{Preparation and culture of Schwann cells-alginic acid sodium hydrogel}

Alginic acid sodium dry powder was dissolved in tri-distilled water. Following $2 \mathrm{~h}$ of magnetic stirring and $0.22 \mu \mathrm{m}$ filtration membrane degerming, alginic acid sodium solution was preserved at $4^{\circ} \mathrm{C}$ for future use. Schwann cells were added to alginic acid sodium solution. Repeated resuspension was performed to adjust cell density at (1.0-5.0) $\times 10^{6} / \mathrm{l}$.

Following $10-\min 1.04 \%$ Cac gelatinization, the resulting products were transferred into a 24-well plate, in which DMEM/F12 was added, for culture in a $5 \% \mathrm{CO}_{2}$ environment at $37^{\circ} \mathrm{C}$. Cell growth was daily observed through the use of an inverted microscope.

\section{Schwann cell counting}

At 2 weeks of culture, Schwann cells-alginic acid sodium hydrogel were taken out, washed with physiological saline, dissolved with a mixed solution of EDTA and citrate sodium, slightly shaken at $37^{\circ} \mathrm{C}$ for $10 \mathrm{~min}$ to separate cell clumps, centrifuged at $1200 \mathrm{r} / \mathrm{min}$ for $5 \mathrm{~min}$, treated with a mixed solution of $0.25 \%$ trypsin and $0.05 \mathrm{mM}$ EDTA, screened with 100-mesh filter membrane, and finally quantitated. At the same time, the digested cells were inoculated onto slides. Following 24-hour complete attachment, cells were fixed with $40 \mathrm{~g} / \mathrm{l}$ paraformaldehyde. Schwann cell purity was identified by S-100 immunohistochemistry as over $96 \%$.

\section{Animal grouping and preparation of spinal cord transaction models}

The SD rats were randomly divided into 4 groups $(n=30)$ : normal control, simple injury, Schwann cells, and Schwann cells-alginic acid sodium hydrogel. Rat models of spinal cord transaction at segment were established in the latter 3 groups. Precisely, following intraperitoneal anesthesia by injection of $3 \%$ pentobarbital sodium (30 mg/kg), a median incision was made to expose the spinous process and vertebral plate. The dura mater was cut open along the median line. The spinal cord was transversely cut open using iridotomy and 1-mm spinal cord tissue segment was taken. Gelatin sponge blocks containing Schwann cell suspension were transplanted in the Schwann cell group. In the Schwann cells-alginic acid sodium hydrogel group, a piece of gelatin sponge block absorbing 10 I of Schwann cells-alginic acid sodium gelatinized cells, which anastomosed cavity stumps in size, was implanted into the cavity; spinal dura mater was sutured using 9-0 silk suture, and incisions were sewed with 1-0 silk suture. No treatments were performed in the normal control and simple injury groups.

\section{Assessment of lower limb locomotor functions}

According to the Basso, Beattie and Bresnahan (BBB) rating scale [2], postoperative locomotor function was scored. 


\section{Sampling harvesting}

At $12 \mathrm{~h}, 1,3,7$, and 21 days after surgery, $6 \mathrm{SD}$ rats were selected from each group, and approximately $10 \mathrm{~mm}$ spinal cord tissue segments were taken, postfixed with $40 \mathrm{~g} / \mathrm{l}$ paraformaldehyde for $24 \mathrm{~h}$, fragmented into two parts at the transection plane, routinely paraffin embedded, and 5 m-thickness serially sectioned. Finally, these sections were subjected to immunohistochemistry and in situ end-labeling staining.

\section{TUNEL staining and cell quantification}

TUNEL staining was performed according to kit instructions. Under 400× magnification, TUNEL sections were observed. The cells with brown nuclei were determined as TUNEL-positive cells. Ten visual fields were randomly selected from each section. TUNEL-positive cells were quantitated.

\section{Detection of $\mathrm{BCl}-2$ expression by immunohistochemistry}

Sections were treated according to the streptavidin-biotin-peroxidase-complex (SABC) method for detection of $\mathrm{BCl}-2$ expression by immunohistochemistry. For a negative control, $\mathrm{Bcl}-2$ primary antibody was not added.

\section{Statistical analysis}

All data were statistically processed using SPSS 11.5 for Windows and were expressed as mean \pm SD. One-way analysis of variance was used for comparison between groups. The Student-Newman-Keuls (SNK) test was employed for pairwise comparison. A level of $p<0.05$ was considered statistically significant.

\section{Results}

\section{Behavioral results}

Following spinal cord transection, the rat lower limb exhibited no or slight joint motion. In each group, rat locomotor function gradually recovered with time, and BBB scores increased gradually but did not reach a normal level. BBB scoring results are shown in Table I.

Analysis of variance results demonstrated that there was no significant difference in BBB scores between groups within 3 days $(p>0.05) ; 7$ days later, in the Schwann cell group and Schwann cellsalginic acid sodium hydrogel group, rat lower limb locomotor function recovered well, BBB scores were increased, and a significant difference existed as compared with other groups $(p<0.05)$. Locomotor function recovered better in the Schwann cellsalginic acid sodium hydrogel group than in the Schwann cell group $(p<0.05)$. In the simple injury group, rat lower limb locomotor function recovered poorly.

\section{TUNEL labeling and cell quantification}

In the normal control group, no apoptotic cells with brown nuclei were observed. In the simple injury group, at 1 day after surgery, spinal cord gray matter exhibited many apoptotic neurons, gray matter structure was severely destroyed, only a small number of nerve cells survived, and the number of TUNEL-labeled cells reached a peak; spinal cord white matter also exhibited many apoptotic neurons, primarily comprising glial cells, but fewer than gray matter. One day later, apoptotic cells were significantly reduced in the Schwann cell and Schwann cells-alginic acid sodium hydrogel groups than in the simple injury group $(p<0.05)$. Apoptotic cells in the Schwann cells-alginic acid sodium hydrogel group were the fewest among all groups $(p<0.05)$.

At 3 days after surgery, there was no significant difference in number of apoptotic cells among simple injury, Schwann cell, and Schwann cells-alginic acid sodium hydrogel groups $(p>0.05)$. At 7 days, the number of apoptotic cells from the simple injury reached the second peak. At the same time, in the Schwann cell and Schwann cells-alginic acid sodium hydrogel groups, gray matter was slightly destroyed, and a small number of apoptotic cells appeared in the gray matter. However, a large number of apoptotic cells, in particular glial cells, were observed in the white matter. Most of the TUNEL-positive cells,

Table I. Basso, Beattie and Bresnahan rating scale scores $(x \pm s, n=30)$

\begin{tabular}{|llccc|}
\hline Time point & Control group & Injury group & Schwann cell group & $\begin{array}{c}\text { Schwann cell-alginic } \\
\text { acid sodium hydrogel group }\end{array}$ \\
\hline $12 \mathrm{~h}$ & $20.52 \pm 0.43$ & $1.02 \pm 0.32$ & $1.26 \pm 0.53$ & $2.01 \pm 0.58$ \\
\hline 1 day & $20.46 \pm 0.60$ & $2.08 \pm 0.38$ & $2.26 \pm 0.52$ & $3.65 \pm 0.39$ \\
\hline 3 days & $20.68 \pm 0.54$ & $2.25 \pm 0.52$ & $3.57 \pm 0.21$ & $4.60 \pm 0.52$ \\
\hline 7 days & $20.67 \pm 0.58$ & $2.67 \pm 0.61$ & $4.50 \pm 0.38^{\mathrm{a}}$ & $7.25 \pm 1.07^{\mathrm{ab}}$ \\
\hline 21 days & $20.60 \pm 0.55$ & $3.33 \pm 0.68$ & $6.06 \pm 0.78^{\mathrm{a}}$ & $10.89 \pm 1.63^{\mathrm{ab}}$ \\
\hline
\end{tabular}

$a_{F}=4.683, p<0.05$, vs. injury group, ${ }^{b} F=4.683, p<0.05$, vs. Schwann cell group 


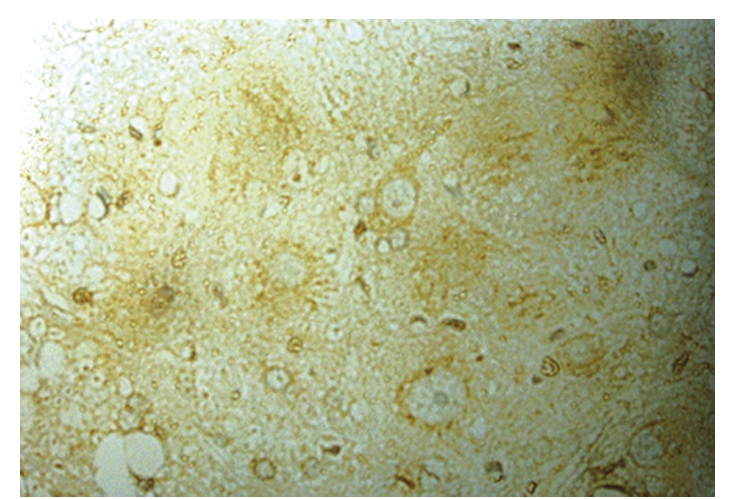

Figure 1. Seven days after injury, the injury group showed hardly any Bcl-2 positive cells (400x)

primarily glial cells, were distributed in the ventral funiculus, lateral funiculus, and dorsal funiculus of white matter. According to cell morphology and distribution, oligodendrocytes took the main place. A significant difference was observed between the simple injury group and the Schwann cell and Schwann cells-alginic acid sodium hydrogel groups ( $p<0.05$, Figures 1,2$)$.

At 21 days, apoptotic cells were hardly observed in each group. Schwann cells-alginic acid sodium hydrogel exhibited significantly greater inhibitory effects on cellular apoptosis than simple Schwann cells $(p<0.01$, Table II).

\section{Bcl-2 immunohistochemistry results}

$\mathrm{Bcl}-2$ immunoreactive cells exhibited brownstained cytoplasm, but the nuclei were not stained. In the normal control group, only a small number of cells were slightly stained, and Bcl-2 immunoreactive cells were not found in the control sections that were treated using normal goat serum without primary antibody. In the Schwann cells-alginic acid sodium hydrogel group, $\mathrm{Bcl}-2$ immunoreactive cells in the injured spinal cord were significantly increased (Figures 3, 4, Table III) until 7 days after surgery and remained at this level for more than 14 days. In the simple injury group, neuronal $\mathrm{Bcl}-2$ immunoreactive expression peaked at 3 days and was close to the normal level at 14 days. Bcl-2 immunoreactive cells were significantly more

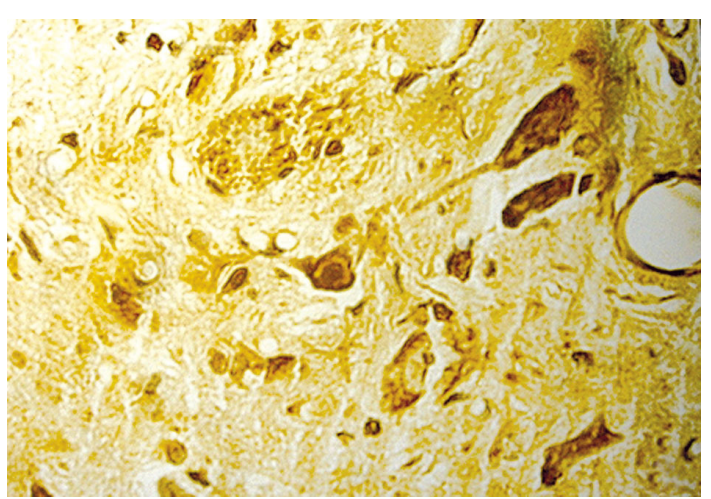

Figure 2. Seven days after injury, the Schwann cellalginic acid hydrogel co-transplanted group showed many $\mathrm{Bcl}-2$ positive cells (400x)

numerous in the Schwann cells-alginic acid sodium hydrogel group than in the simple injury and Schwann cell groups $(p<0.05)$.

\section{Discussion}

Schwann cells exhibit wide biological functions, which play obvious promoting effects on neuronal growth, development, and survival as well as axon growth. Nerve cell apoptosis plays an important role in secondary spinal cord injury. In different spinal cord injury models, nerve cell injury is a common secondary injury, oligodendrocytes are primarily included, and neurons from gray matter are not included [7]. A study reported that a great many apoptotic cells appeared following spinal cord injury, and glial cell apoptosis was widely distributed in injury tissue and adjacent tissue within a long time period [8]. We found that apoptotic glial cells were primarily distributed in the longitudinal nerve tract of white matter, in particular in the demyelinated white matter, which is likely to be a primary cause of demyelination. Following nerve injury, neuronal survival is a prerequisite of neuronal regeneration, while $\mathrm{Bcl}-2$ is an important apoptosis-inhibiting gene; thus excessive expression of $\mathrm{Bcl}-2$ protein can significantly inhibit neuronal apoptosis. Therefore, an increase in Bcl-2 expression not only can protect neurons against different damage factors but can also promote axon regeneration in the adult mammalian nervous system [9-11]. Proto-oncogene

Table II. TUNEL-positive cells among groups ( $x \pm s, n=30$, number per visual field)

\begin{tabular}{|lccc|}
\hline Time point & Injury group & Schwann cell group & $\begin{array}{c}\text { Schwann cell-alginic } \\
\text { acid sodium hydrogel group }\end{array}$ \\
\hline $12 \mathrm{~h}$ & $9.81 \pm 1.47$ & $9.55 \pm 1.05$ & $9.06 \pm 1.41$ \\
\hline 1 day & $26.67 \pm 1.63$ & $18.00 \pm 0.89$ & $14.17 \pm 1.47^{\mathrm{ab}}$ \\
\hline 3 days & $14.50 \pm 1.05$ & $13.00 \pm 1.41$ & $8.83 \pm 1.33$ \\
\hline 7 days & $18.50 \pm 1.64$ & $15.50 \pm 1.05^{\mathrm{a}}$ & $11.17 \pm 1.17^{\mathrm{ab}}$ \\
\hline 21 days & $7.00 \pm 0.89$ & $6.50 \pm 1.05^{\mathrm{a}}$ & $6.00 \pm 0.89^{\mathrm{ab}}$ \\
\hline
\end{tabular}

$a_{F}=4.389, p<0.05$, vs. injury group, ${ }^{b} F=3.983, p<0.05, v s$. Schwann cell group 


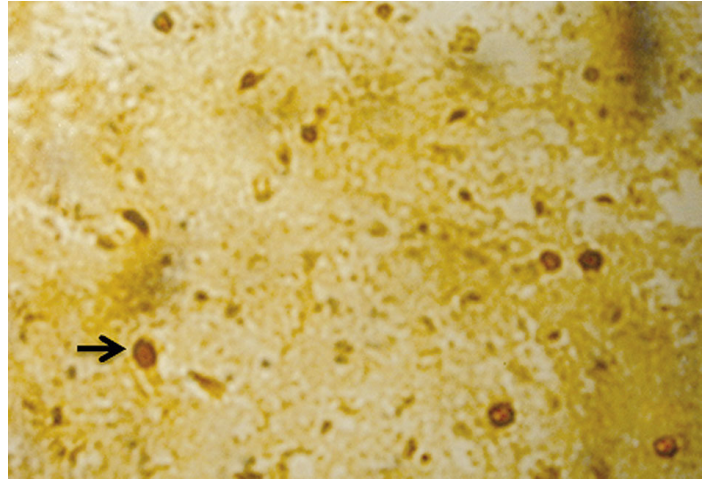

Figure 3. Seven days after injury, the injury group showed many apoptotic cells from TUNEL staining $(400 \times)$

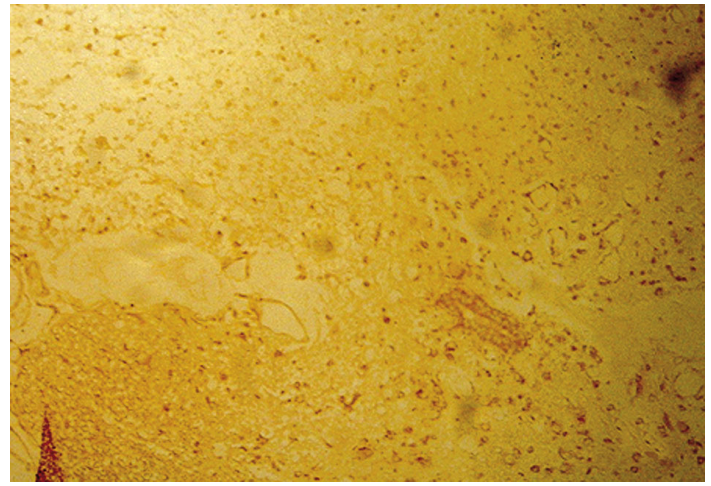

Figure 4. Seven days after injury, the Schwann cellalginic acid hydrogel co-transplanted group showed few apoptotic cells from TUNEL staining (400x)

Table III. Bcl-2 positive cells in spinal cord after injury $(x \pm s, n=30)$

\begin{tabular}{|lccc|}
\hline Time point & Injury group & Schwann cell group & $\begin{array}{c}\text { Schwann cell-alginic } \\
\text { acid sodium hydrogel group }\end{array}$ \\
\hline $12 \mathrm{~h}$ & $61.08 \pm 9.97$ & $60.91 \pm 9.98$ & $71.61 \pm 5.72$ \\
\hline 1 day & $93.40 \pm 10.79$ & $92.54 \pm 11.04$ & $116.47 \pm 10.64^{\mathrm{ab}}$ \\
\hline 3 days & $112.37 \pm 11.19$ & $107.79 \pm 10.51$ & $137.45 \pm 10.93^{\mathrm{ab}}$ \\
\hline 7 days & $76.37 \pm 5.66$ & $75.90 \pm 6.44$ & $151.80 \pm 11.61^{\mathrm{ab}}$ \\
\hline 21 days & $32.29 \pm 3.22$ & $29.18 \pm 3.21$ & $148.73 \pm 11.73^{\mathrm{ab}}$ \\
\hline
\end{tabular}

$a_{F}=5.689, p<0.05$, vs. injury group, ${ }^{b} F=3.983, p<0.05$, vs. Schwann cell group

$\mathrm{Bcl}-2$ inhibits cellular apoptosis through inhibition of caspase by $\mathrm{BCl}-2$.

Alginic acid is extracted from brown algae. Its sodium salt can be degraded and absorbed in vivo by hydrolysis and enzymolysis and exhibits good biocompatibility which benefits regenerated axon growth and Schwann cell migration in the peripheral nerve. The present results demonstrated that alginic acid sodium is a good carrier of Schwann cells, and it is feasible to treat spinal cord injury by Schwann cells-alginic acid sodium hydrogel transplantation. Schwann cells-alginic acid sodium hydrogel transplantation exhibits effects on secondary spinal cord injury caused by glial cell apoptosis. Based on immunohistochemistry results, it is presumed that within $8 \mathrm{~h}$ to 1 day after surgery, the cellular apoptotic rate reached the first peak, which rapidly switched on the gradually up-regulated $\mathrm{Bcl}-2$ protein expression, and the cellular apoptosis rate was decreased to the lowest level at 3 days, but $\mathrm{Bcl}-2$ protein expression was rapidly decreased from the peak level at 3 days, so the inhibitory effects of $\mathrm{BCl}-2$ protein was gradually weakened, and therefore a second peak of the cellular apoptotic rate appeared at 7 days. In the Schwann cells-alginic acid sodium hydrogel group, the number of apoptotic cells in the injured spinal cord reached a peak at 1 day; Bcl-2 protein expression sharply ascended within $8 \mathrm{~h}$ to 3 days, reached a peak level at 7 days, and remained at this level for more than 14 days; thus, the cellular apoptosis rate was controlled at a very low level. A second peak of cellular apoptosis did not appear, in contrast with the injury and Schwann cell group. The present results demonstrated that Schwann cells-alginic acid sodium hydrogel transplantation promoted persistent high expression of $\mathrm{Bcl}-2$ protein in cells from injured spinal cord, thereby inhibiting neuronal and glial cell apoptosis.

Following Schwann cells-alginic acid sodium hydrogel transplantation, rat BBB scores were increased, demonstrating that spinal function was partially recovered. This also indicates that Schwann cells-alginic acid sodium hydrogel transplantation exhibits anti-apoptotic effects and neuronal protective effects. The underlying mechanisms include: (1) Schwann cells can secrete many neurotrophic factors, (2) Schwann cells can prevent nerve demyelination, (3) Schwann cells, as specific glial cells, can produce many adhesion factors and exhibit protective effects in conjunction with nerve cells [1, 12], (4) Alginic acid hydrogel can exert beneficial effects on Schwann cells, and integrate well into the spinal cord tissue, which has also been shown in other cells and tissues [13-15].

In conclusion, the co-transplantation of Schwann cells in alginic acid sodium hydrogel showed prospective applications in repairing the spinal cord injury. Future studies are still required to elucidate the underlying mechanisms. 


\section{Acknowledgments}

Haibao Wang and Chibo Liu contributed equally to this work.

\section{References}

1. Lavdas AA, Papastefanaki F, Thomaidou D, Matsas R. Schwann cell transplantation for CNS repair. Curr Med Chem 2008; 15: 151-60.

2. Oudega $M, X u X M$. Schwann cell transplantation for repair of the adult spinal cord. J Neurotrauma 2006; 23: 453-67.

3. Nomura $\mathrm{H}$, Tator $\mathrm{CH}$, Shoichet MS. Bioengineered strategies for spinal cord repair. J Neurotrauma 2006; 23: 496-507.

4. Tabesh H, Amoabediny G, Nik NS, et al.The role of biodegradable engineered scaffolds seeded with Schwann cells for spinal cord regeneration. Neurochem Int 2009; 54: 73-83.

5. Brockes JP, Fields KL, Raff MC. Studies on cultured rat Schwann cells. I. Establishment of purified populations from cultures of peripheral nerve. Brain Res 1979; 165: 105-18.

6. Cai XX, Luo E, Yuan Q. Interaction between Schwann cells and osteoblasts in vitro. Int J Oral Sci 2010; 2: 74-81.

7. Li GL, Farooque M, Olsson Y. Changes of Fas and Fas ligand immunoreactivity after compression trauma to rat spinal cord. Acta Neuropathol 2000; 100: 75-81.

8. Park E, Liu Y, Fehlings MG. Changes in glial cell white matter AMPA receptor expression after spinal cord injury and relationship to apoptotic cell death. Exp Neurol 2003; 182: 35-48.

9. Chen DF, Tonegawa S. Why do mature CNS neurons of mammals fail to re-establish connections following injury: functions of bcl-2. Cell Death Differ 1998; 5: 816-22.

10. Schaller B, Graf R, Jacobs AH. Ischaemic tolerance: a window to endogenous neuroprotection? Lancet 2003; 362: 1007-8.

11. Teng FY, Tang BL. Axonal regeneration in adult CNS neurons: signaling molecules and pathways. J Neurochem 2006; 96: 1501-8.

12. Tetzlaff W, Okon EB, Karimi-Abdolrezaee S, et al. A systematic review of cellular transplantation therapies for spinal cord injury. J Neurotrauma 2011; 28: 1611-82.

13. Frampton JP, Hynd MR, Shuler ML, Shain W. Fabrication and optimization of alginate hydrogel constructs for use in 3D neural cell culture. Biomed Mat 2011; 6: 015002.

14. Nunamaker EA, Otto KJ, Kipke DR. Investigation of the material properties of alginate for the development of hydrogel repair of dura mater. J Mech Behav Biomed Mater 2011; 4: 16-33.

15. Zhao L, Weir MD, Xu HH. An injectable calcium phosphatealginate hydrogel-umbilical cord mesenchymal stem cell paste for bone tissue engineering. Biomaterials 2010; 31: 6502-10. 